\title{
EFEITOS DO DESEMPREGO, DO AUXÍLIO EMERGENCIAL E DO PROGRAMA EMERGENCIAL DE PRESERVAÇÃO DO EMPREGO E DA RENDA (MP № 936/2020) SOBRE A RENDA, A POBREZA E A DESIGUALDADE DURANTE E DEPOIS DA PANDEMIA ${ }^{1,2}$
}

Rogério Jerônimo Barbosa ${ }^{3}$ Ian Prates ${ }^{4}$

\section{INTRODUÇÃO}

Neste artigo, avaliamos os efeitos da incidência conjunta das quedas do nível de ocupação do Programa Emergencial de Preservação do Emprego e da Renda (Medida Provisória - MP no 936/2020) e da Renda Básica Emergencial - RBE (Lei nº 13.982/2020) sobre a distribuição da renda domiciliar per capita e a pobreza. Essas medidas foram tomadas para mitigar as consequências socioeconômicas da pandemia e das necessárias medidas de isolamento social e impactaram fortemente a atividade econômica, o mercado de trabalho e a renda das famílias, tal como já indicado pelos primeiros dados divulgados pelo Cadastro Geral de Empregados e Desempregados (Caged), pela Pesquisa Nacional por Amostra de Domicílios Contínua (PNAD) Contínua (trimestre de fevereiro, março e abril de 2020) e pela PNAD-Covid-19.

Alguns estudos recentes já se debruçaram sobre essas políticas, embora com objetivos distintos dos aqui propostos. Komatsu e Menezes-Filho (2020) concluíram que a RBE poderia atenuar fortemente a queda da renda e o aumento da pobreza, em vários cenários de desemprego. Hecksher e Foguel (2020) avaliaram a cobertura potencial da RBE e do Programa Emergencial de Preservação do Emprego e da Renda e apontaram que essas medidas poderiam atingir, conjuntamente, até $80 \%$ da população. Costa e Reis (2020) avaliaram o potencial efeito da MP no 936/2020 sobre a renda do trabalho e a renda domiciliar per capita e concluíram que a medida tem pouco impacto sobre os trabalhadores com renda do trabalho menor que três salários mínimos e impactos heterogêneos nos estratos superiores.

Contribuímos para esse rol de análises isolando os efeitos de cada um desses fatores e formamos cenários de evolução do possível quadro socioeconômico. Ao final, identificamos como um quadro pós-pandemia e sem auxílios/compensaçóes pode se configurar. O texto é dividido em seis seçôes, incluindo esta introdução. A seção 2 apresenta brevemente alguns

1. DOI: http://dx.doi.org/10.38116/bmt69/notastecnicas2

2. Resultados preliminares deste trabalho foram apresentados em Barbosa et al. (2020). Os autores agradecem aos demais membros da equipe: Hellen Guicheney, Sérgio Simoni Junior, Carolina Requena, Paulo Flores, Heloísa Fimiani, Eduardo Lazzari, Thiago Meireles, Vitor Menezes e João Lucas de Oliveira. Os autores também agradecem à Fapesp pelo apoio financeiro para a realização desta pesquisa (Processo no 2018/13863-0).

3. Pesquisador do Centro de Estudos da Metrópole da Universidade de São Paulo (USP).E-mail: <antrologos@gmail.com>.

4. Pesquisador do Centro Brasileiro de Análise e Planejamento (Cebrap) e da Social Accountability International (SAI). E-mail: $<$ ianprates@cebrap.org.br>. 
aspectos básicos da RBE e da MP no 936/2020 e os efeitos esperados. A seção 3 discute nossa estratégia analítica, baseada em microssimulações que visam "atualizar" os dados do período anual da PNAD Contínua 2019 para representar o contexto brasileiro em torno de abril e maio de 2020. A seção 4 discute aspectos metodológicos do estudo. Na seção 5, apresentamos os resultados. Por fim, a seção 6 traz algumas considerações finais.

\section{AS POLÍTICAS EMERGENCIAIS E SEUS EFEITOS ESPERADOS}

\subsection{RBE}

A RBE consiste na transferência incondicional de três parcelas de $\mathrm{R} \$ 600,00$ para a população considerada elegível, segundo as regras do programa. A sua prorrogação é dada como quase certa; no entanto, ainda não há clareza quanto ao prazo de extensão ou ao valor dos benefícios futuros. ${ }^{5}$ Em meados de junho de 2020, o benefício atingia 61 milhões de pessoas. ${ }^{6}$ A título de comparação, o Programa Bolsa Família (PBF) amparava, em abril de 2020, um total de 14,3 milhóes de famílias (43,7 milhóes de pessoas ao todo), com um benefício médio por família de $\mathrm{R} \$ 175,00 .^{7}$

O valor superior da RBE, se comparada ao PBF, traz expectativa de que atue positivamente para uma redução da pobreza e da desigualdade, mesmo durante a pandemia. O valor médio do benefício chega a ser superior à renda domiciliar dos mais pobres - ou seja: para muitos, isso representa uma adição de renda inédita. A transferência de uma quantia monetária por um curto período pré-definido (e durante uma recessão), contudo, não é capaz de alterar, de maneira duradoura, outras formas de privação que incidem particularmente sobre os mais pobres. Por isso, a expectativa de queda da pobreza conforme medida por indicadores de renda não se confunde com a queda da pobreza concebida de modo multidimensional. Mas, de um ponto de vista contrafactual, a RBE certamente terá evitado consequências ainda mais desastrosas, que teriam ocorrido no caso de sua inexistência.

\section{$2.2 \mathrm{MP}$ no $936 / 2020$}

Esta medida estimula que empregadores e empregados entrem em acordo para redução da jornada de trabalho e do salário. A redução pode ser de $25 \%, 50 \%$ ou $70 \%$, por até três meses ou então a completa suspensão do contrato de trabalho. Nesse contexto, o governo concede um benefício complementar, baseado no valor de seguro-desemprego ao qual o trabalhador

5. No momento do fechamento deste texto, o Executivo federal pressionava por mais dois pela redução do auxílio para $\mathrm{R} \$ 300,00$; o Congresso estava inclinado à extensão até o fim de 2020 com manutenção dos $R \$ 600,00$.

6. Os dados da Caixa Econômica Federal sobre o auxílio emergencial estão disponíveis em: <https://bit.ly/321BQwz>.

7. Para mais informações, acessar o portal do Ministério da Cidadania. Disponível em: <https://aplicacoes.mds.gov.br/sagi>. 
teria acesso, dado seu nível de renda. ${ }^{8}$ Até 26 de maio de 2020, haviam sido selados 8.154.997 acordos. Desse total, 4,4 milhōes foram de caráter suspensivo, 1,2 milhão com redução de jornada de 25\%, 1,4 milhão com redução de 50\%, 991 mil com redução de $70 \%$ - e pouco mais de 160 mil foram postos de trabalho intermitentes, que não se relacionam propriamente com a MP no 936/2020.

Como a MP no 936/2020 incide sobre o emprego formal reduzindo a renda do trabalho, espera-se que atue de forma a diminuir a renda domiciliar per capita, aumentando levemente a taxa de pobreza. Além disso, como os trabalhos formais são mais concentrados na metade superior da distribuição, espera-se que as reduçóes de jornada e salários minimizem a desigualdade de renda, durante a vigência da medida. Cabe, no entanto, destacar que esse programa atinge um número de pessoas consideravelmente menor do que a RBE. Por essa razão, esperamos efeitos de menor intensidade.

\section{ESTRATÉGIA ANALÍTICA: MICROSSIMULAÇÃO DA INCIDÊNCIA COMBINADA DO DESEMPREGO, DA MP № 936/2020 E DA RBE}

De acordo com a PNAD Contínua do trimestre de fevereiro, março e abril de 2020, 70\% dos desligamentos recentes teriam ocorrido no setor informal. No entanto, mais da metade desse período é caracterizada por ausência de impactos econômicos da pandemia. Como forma de obter cenários atualizados, combinamos diversas fontes de dados. Nesse sentido, utilizamos a versão anualizada da PNAD Contínua 2019, que contém informações mais completas sobre os domicílios, ${ }^{9}$ e seguimos os passos, conforme descrito a seguir.

1) Simulamos a incidência de desligamentos em postos do setor formal e informal, sob suposiçóes traçadas a informaçôes do Caged.

2) Simulamos a incidência dos acordos da MP no 936/2020, a partir dos dados divulgados pelo Ministério da Economia.

3) Simulamos a incidência da RBE, aplicando as regras de elegibilidade conforme operacionalizadas por Souza et al. (2020).

Detalhes da operacionalização desses passos serão fornecidos na seção 4, que aborda a metodologia. A figura 1 resume a ideia geral e as etapas da microssimulação.

8. Uma descrição mais detalhada da MP no 936/2020 pode ser encontrada em Costa e Reis (2020).

9. Não utilizamos o método de identificação de meses específicos proposto por Hecksher (2020), pois os dados trimestrais, aos quais se aplicam, não contêm rendimentos que não do trabalho. 
FIGURA 1

Microssimulação da incidência do desemprego, da MP no 936/2020 e da RBE

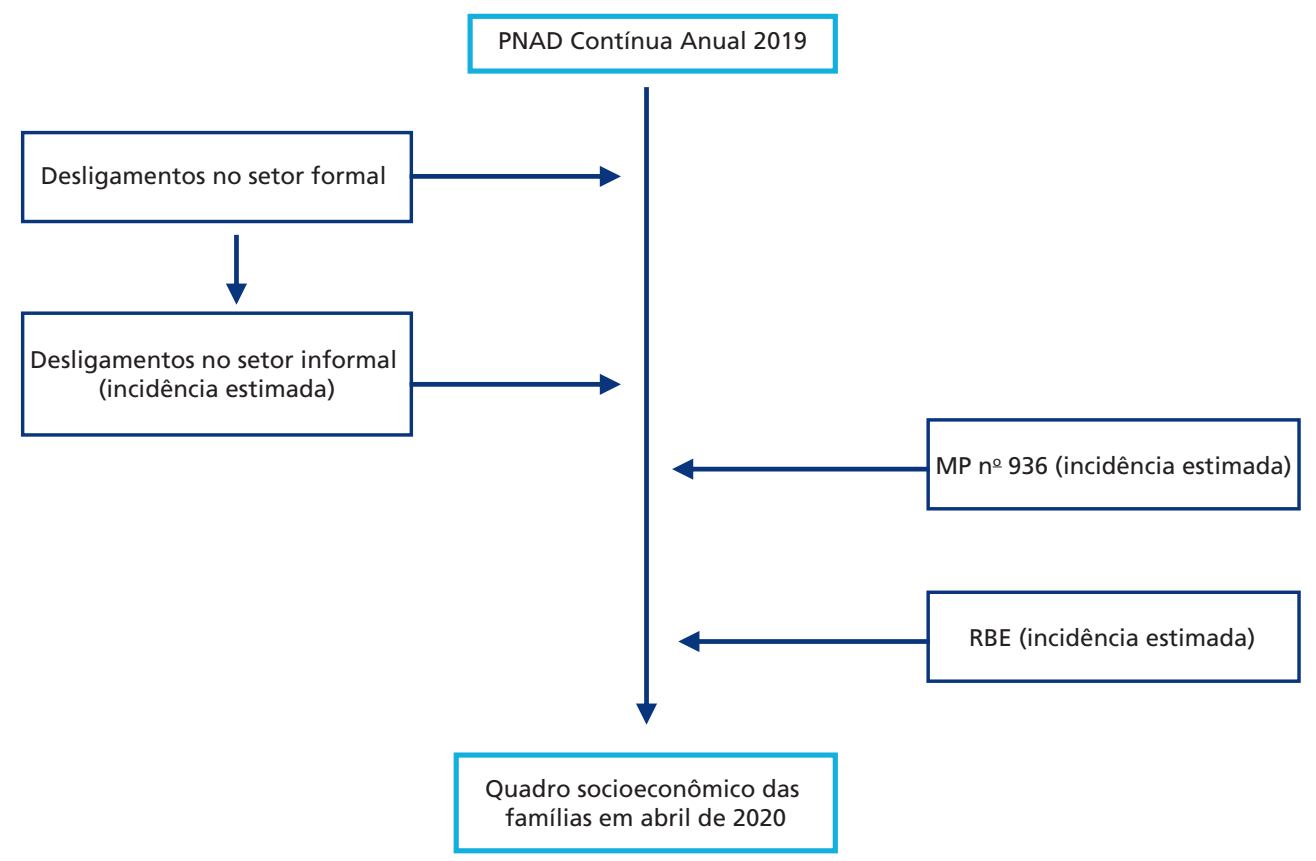

Elaboração dos autores.

\section{METODOLOGIA}

\subsection{Dados}

Os microdados do período anual da PNAD Contínua 2019 (primeiras visitas) são nossa principal fonte. Os rendimentos foram deflacionados para preços médios de 2019, com os deflatores do Instituto Brasileiro de Geografia e Estatística (IBGE); em seguida, para valores de março de 2020, com uso do Índice Nacional de Preços ao Consumidor (INPC). No cálculo da renda domiciliar, excluímos agregados que não contribuem para despesas, pensionistas, empregados domésticos e seus parentes que residem no domicílio. Consideramos como formais: $i$ ) os empregados que possuem carteira de trabalho; ii) militares e estatutários; e iii) empregadores e contas-própria que contribuem para o Instituto Nacional do Seguro Social (INSS) e/ou possuem Cadastro Nacional da Pessoa Jurídica (CNPJ). Utilizamos também dados agregados sobre os saldos de emprego do Novo Caged (por setores e Unidades da Federaçáo) e informações sobre o número de acordos da MP no 936/2020 (por setores e tipos de acordo). Todas as análises foram realizadas na linguagem $R$. Dados e scripts para replicação completa podem ser requisitados aos autores. 


\subsection{Estimando o desemprego durante a pandemia}

Para simular cenários de desemprego, sorteamos aleatoriamente indivíduos ocupados no período anual da PNAD Contínua 2019, atribuímos a eles o status de desocupados e igualamos a zero suas rendas habituais de todos os trabalhos. Para empregados com carteira assinada, sorteamos uma fração idêntica ao saldo acumulado dos desligamentos por setores de atividade econômica acumulados em março e abril de 2020, divulgado no Caged pelo Ministério da Economia (tabela 6.1, resultados com ajustes).

Dentro de cada setor, para cada empregado celetista selecionado no passo anterior, sorteamos 2,33 trabalhadores informais (independentemente da posição na ocupação) e os tornamos desocupados. Assim, mantemos a proporção de desligamentos de postos formais e informais observada na PNAD Contínua do trimestre móvel de fevereiro a abril. A hipótese é a de que a distribuição setorial seria idêntica para os segmentos, diferindo apenas em escala. O único setor informal para o qual essa regra não foi seguida foi o de serviços domésticos, pois o Caged reflete mal o que ocorre entre os sem carteira e contas-própria nesse segmento. Nossas simulaçóes pressupóem que $40 \%$ dos trabalhadores domésticos informais foram desligados e/ou encontram-se sem rendimentos do trabalho. Construímos três cenários de desemprego.

O cenário 1 replica as proporções de desligamentos acumulados em março e abril de 2020 no Caged. Os cenários 2 e 3 multiplicam essas proporçôes por dois e três, respectivamente.

\subsection{Identificação dos acordos da MP no 936/2020}

Com base nas informações do Caged sobre a distribuição de acordos para redução de jornada e salários, sorteamos aleatoriamente empregados celetistas na PNAD Contínua e os identificamos como incluídos no programa da MP nº 936/2020. Os dados divulgados pelo Ministério da Economia, entretanto, não informam as distribuiçôes dos acordos por tipo e setores de atividade econômica simultaneamente. Dessa forma, construímos essas células partindo da suposição simplificada de que a proporção dos tipos de acordos dentro de cada setor seria sempre igual - ou seja, uma hipótese de independência. Para isso fazemos:

$$
\begin{gathered}
\mathrm{P}(\text { tipo do acordo }=k \mid \text { setor, posição }=\text { empregado CLT }) \\
=\mathrm{P}(\text { tipo }=k \mid \text { acordo } \\
=\text { sim }) \times \mathrm{P}(\text { acordo }=\text { sim } \mid \text { setor }, \text { posição }=\text { Empregado CLT }), \\
=\frac{n_{\text {tipo de acordo }=k}}{n_{\text {total de acordos }}} \times \frac{n_{\text {total de acordos } \mid \text { setor }=j}}{n_{\text {setor }=j \mid \text { Empregado } C L T}}
\end{gathered}
$$

em que ; os valores para , e foram obtidos da apresentação oficial dos dados do Caged, feita pelo Ministério da Economia (Brasil, 2020, p. 30-31). O valor de foi estimado com os dados do período anual da PNAD Contínua 2019. Com isso, obtemos a distribuição das probabilidades de sorteio dos empregados celetistas por tipo de acordo, condicional aos setores de atividade. 
TABELA 1

Probabilidades de sorteio por tipo de acordo, em cada setor (Em \%)

\begin{tabular}{|c|c|c|c|c|c|}
\hline \multirow{2}{*}{ Setor } & \multicolumn{3}{|c|}{ Redução de jornada e salário } & \multirow{2}{*}{$\begin{array}{l}\text { Suspensão } \\
\text { do contrato }\end{array}$} & \multirow{2}{*}{ Setor - tota } \\
\hline & 25 & 50 & 70 & & \\
\hline Agropecuária & 0,20 & 0,26 & 0,18 & 0,80 & 1,43 \\
\hline Comércio & 3,47 & 4,41 & 3,06 & 13,68 & 24,62 \\
\hline Construção & 1,86 & 2,37 & 1,64 & 7,36 & 13,24 \\
\hline Indústria geral & 3,41 & 4,34 & 3,01 & 13,47 & 24,23 \\
\hline Outros & 11,95 & 15,19 & 10,53 & 47,14 & 84,81 \\
\hline Serviços & 2,94 & 3,74 & 2,59 & 11,59 & 20,85 \\
\hline
\end{tabular}

Fonte: Brasil (2020, p. 30-31).

Elaboração dos autores.

Para cada indivíduo sorteado, procedemos a redução dos rendimentos habituais do trabalho, segundo as regras da MP no 936/2020. Em seguida, adicionamos o Benefício Emergencial de Preservação do Emprego e da Renda, conforme o valor equivalente do seguro-desemprego (dado o nível original da renda) e o tipo de acordo.

\subsection{Identificação dos beneficiários da RBE}

Para a operacionalização dos critérios de elegibilidade à RBE, adotamos a mesma estratégia elaborada por Souza et al. (2020) - replicada também por Hecksher e Foguel (2020). Assumiremos que todos os indivíduos identificados como "elegíveis" se tornam efetivos beneficiários do programa. Uma vez que esse método já foi utilizado por outros autores, por concisão, não exporemos aqui os critérios e passos da operacionalização. Recomendamos a consulta ao trabalho original de Souza et al. (2020) e deixamos disponíveis nossos códigos em $R$ para replicação completa dessa operacionalização.

\subsection{Simulações e efeitos sobre a renda, a pobreza e a desigualdade}

Nossas simulaçóes são probabilísticas, o que implica que os sorteios de indivíduos para atribuição do desemprego e dos acordos da MP no 936/2020 seriam diferentes em cada ensaio. Mas, pela lei dos grandes números, os indicadores convergem em probabilidade para os valores verdadeiros. Como a quantidade de sorteados é numerosa, a variância dos resultados é pequena, fazendo com que diferenças entre sorteios sejam inexpressivas.

Os principais indicadores de interesse são: o nível de emprego, a renda domiciliar per capita, o coeficiente de Gini e a taxa de pobreza. Nesse contexto, identificamos como pobres os indivíduos com renda domiciliar per capita inferior a um terço do salário mínimo vigente em 2020 (R \$ 1.045,00). Podemos escrever que, em nossas simulaçóes, qualquer indicador será funçáo do cenário de desemprego adotado, da incidência da MP no 936/2020 e da incidência 
e valores da RBE: . O baseline de cada indicador é obtido quando substituímos na função os valores observados em 2019 (no caso da MP no 936/2020, sua inexistência; no caso da RBE, um benefício de valor igual a zero). Lançamos mão da proposta de Shorrocks (2013), para obter efeitos marginais por meio do valor esperado de todas combinaçóes de diferenças finitas (Shapley value). Para isso, utilizamos o pacote Shapley, desenvolvido para a linguagem $R$ (Elbers, 2019).

\section{RESULTADOS}

\subsection{Os efeitos marginais}

A tabela 2 apresenta o efeito marginal dos cenários de desemprego e de cada um dos programas. A leitura dos efeitos deve ser sempre realizada sob a suposição de que tudo mais permaneceria constante. Assim, adicionando os efeitos líquidos ao baseline, é possível construir arbitrariamente diversos contrafactuais. Em linhas gerais, o padrão comporta-se como o esperado: o desemprego, a inatividade e a MP n⿳0 936/2020 têm um efeito negativo sobre a renda e a pobreza, ao passo que a RBE tem efeitos positivos.

TABELA 2

Efeitos marginais das políticas sobre o trabalho e os rendimentos

\begin{tabular}{|c|c|c|c|c|c|c|c|}
\hline \multirow[b]{2}{*}{ Indicador } & \multirow[b]{2}{*}{ Baseline } & \multicolumn{2}{|c|}{ RBE } & \multicolumn{3}{|c|}{ Desemprego } & \multirow{2}{*}{$\begin{array}{c}M P \text { no } \\
936 / 2020\end{array}$} \\
\hline & & $\begin{array}{c}R \$ 300 \\
\quad, 00\end{array}$ & $\begin{array}{c}R \$ \\
600,00\end{array}$ & Cenário 1 & Cenário 2 & Cenário 3 & \\
\hline Desocupação & $11,7 \%$ & - & - & 4,6 p.p. & 7,3 p.p. & 10,0 p.p. & - \\
\hline Nível de ocupação & $55,3 \%$ & - & - & $-2,9$ р.p. & $-4,5$ p.p. & -6,3 p.p. & - \\
\hline Renda domiciliar per capita ( $R \$$ ) & 1.442 & 89 & 178 & -27 & -47 & -66 & -29 \\
\hline Pobreza & $18,7 \%$ & $-9,7$ p.p. & $-16,5$ p.p. & 1,4 p.p. & 2,2 p.p. & 3,2 p.p. & 0,1 p.p. \\
\hline Coeficiente de Gini & 0,543 & $-0,0502$ & $-0,0900$ & 0,0080 & 0,0125 & 0,0179 & $-0,0028$ \\
\hline
\end{tabular}

Fonte: PNAD Contínua 2019 - período anual (primeiras visitas).

Elaboração dos autores.

Obs.: 1. A linha de pobreza adotada é de um terço do salário mínimo vigente em 2020.

2. p.p. $=$ pontos percentuais.

Uma RBE de R\$300,00 seria responsável por um acréscimo de R \$ 89,00 na renda domiciliar per capita, ao passo que um benefício de $\mathrm{R} \$ 600,00$ a elevaria para $\mathrm{R} \$ 178,00$. Os impactos sobre a pobreza e a desigualdade são também muito expressivos. No primeiro caso, a pobreza cairia 9,7 p.p.; no segundo, 16,5 p.p. Vale ressaltar, novamente, que a pobreza medida de forma monetária, durante a pandemia e a vigência do auxílio emergencial, é simplesmente uma medida ainda mais limitada de pobreza.

Com respeito ao desemprego, a intensidade dos efeitos aumenta de modo linear ao longo de cada cenário. No cenário 3, o mais intenso, haveria um aumento de 10,0 p.p. na taxa de 
desocupação e uma queda de 6,3 p.p. no nível de emprego (número de ocupados dividido pela populaçáo em idade ativa - PIA). A renda domiciliar per capita sofreria uma queda de $\mathrm{R} \$ 66,00$, e os aumentos na pobreza e no coeficiente de Gini seriam de 3,2 p.p. e 0,018, respectivamente.

Os efeitos da MP no 936/2020 são, como esperado, menos intensos. Eles provocariam uma redução de, aproximadamente, $\mathrm{R} \$ 30,00$ na renda domiciliar per capita, um aumento quase insignificante da pobreza (uma vez que os elegíveis náo estấo próximos ao limiar da linha de pobreza) e uma queda de 0,003 no coeficiente de Gini - posto que, ao reduzir a renda dos estratos da metade superior da distribuição, provoca um nivelamento ou equalizaçáo.

\subsection{Desemprego estimado e comparação com a PNAD-Covid-19}

Nesta subseçáo, combinamos os efeitos marginais identificados anteriormente para gerar cenários sequenciais que representam sucessóes ao longo do tempo. Elaboramos diagramas com cinco etapas. A linha básica dessas sequências orienta-se pela evoluçâo do desemprego, partindo do baseline, passando por cada cenário de desemprego e entáo se sustentando no cenário 3 por um período adicional. O gráfico 1 ilustra o que ocorre com a taxa de desocupação e com o nível de ocupação sob essas suposiçóes.

\section{GRÁFICO 1}

\section{Desemprego e nível de ocupação nos cenários sequenciais simulados}

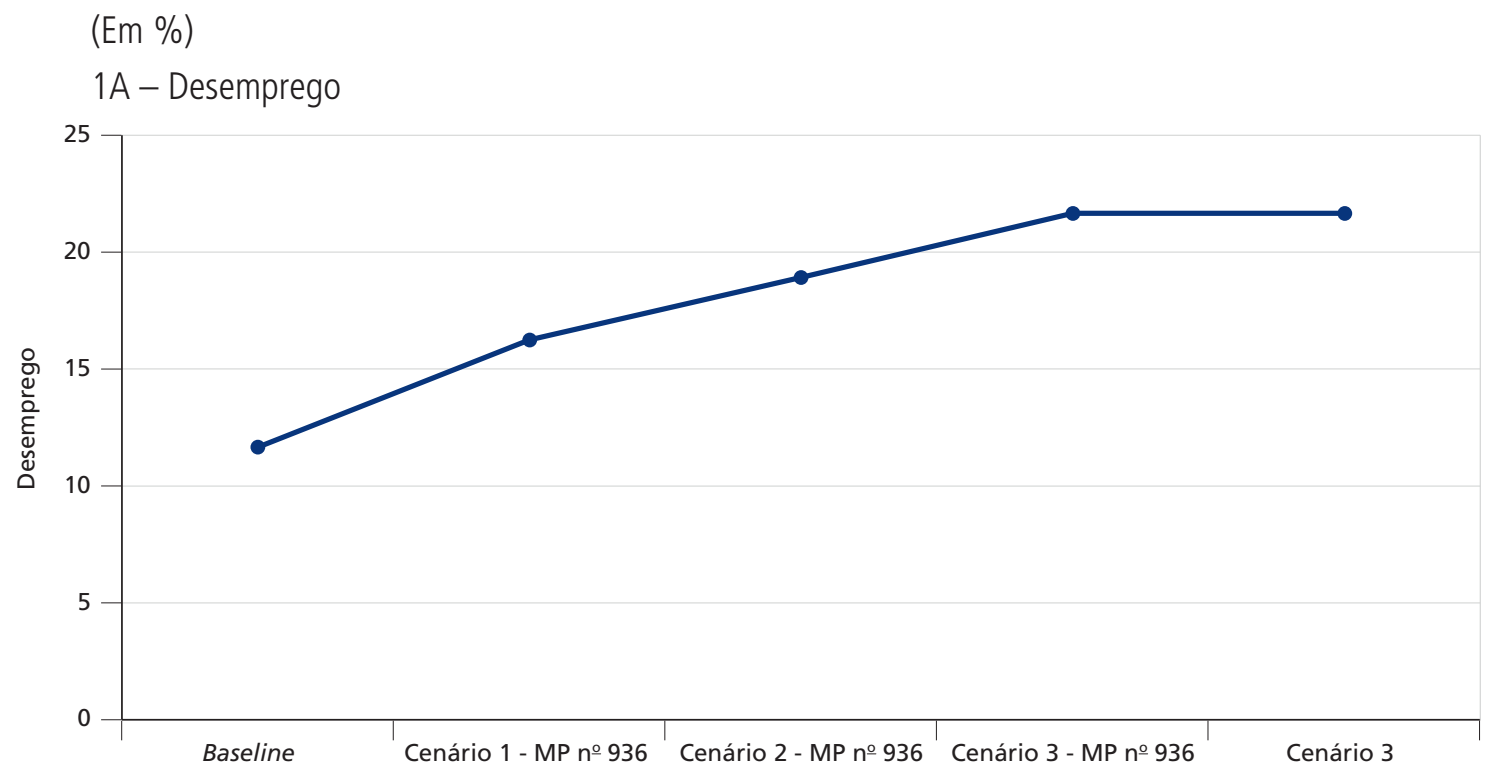




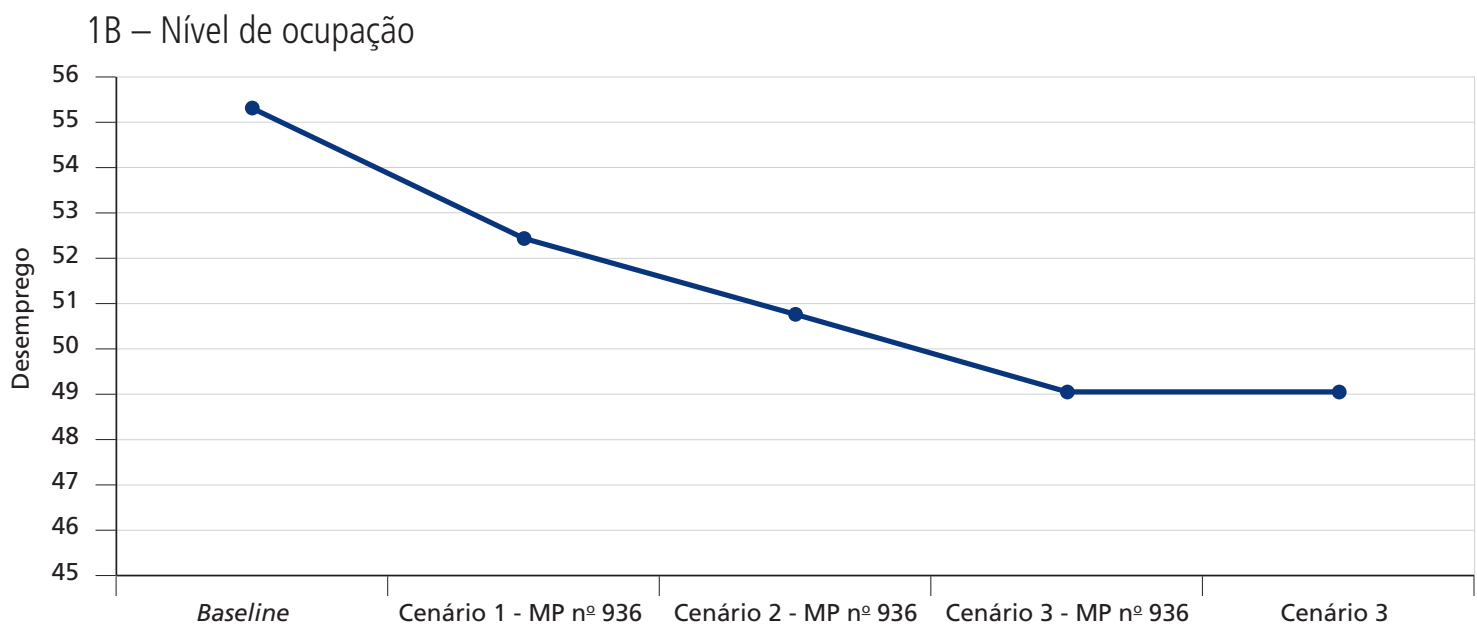

Fonte: PNAD Contínua 2019 - período anual (primeiras visitas).

Elaboração dos autores.

Os dados recém-divulgados da PNAD-Covid-19, a despeito das diferenças metodológicas, permitem uma validação de face desses resultados. Nessa pesquisa, o nível de ocupação observado foi de 49,7\%, na última semana de maio - ao passo que nossa estimativa indica 49,1\%. Estaríamos, desse modo, no início de junho, experimentando um contexto que pode ser aproximado pelo cenário 3 de desemprego. O gráfico 2 traz o nível de ocupação ao longo de toda série de trimestres móveis da PNAD Contínua e acrescenta o dado da PNAD-Covid-19 para a última semana de maio e nossa estimativa. Pela primeira vez, na série histórica, haveria mais adultos náo ocupados do que ocupados. A queda do nível de emprego teria se dado principalmente entre o meio de março e o fim de abril.

\section{GRÁFICO 2}

Nível de ocupação: PNAD Contínua, PNAD-Covid 19 e nossa estimativa (2012-2020) (Em \%)

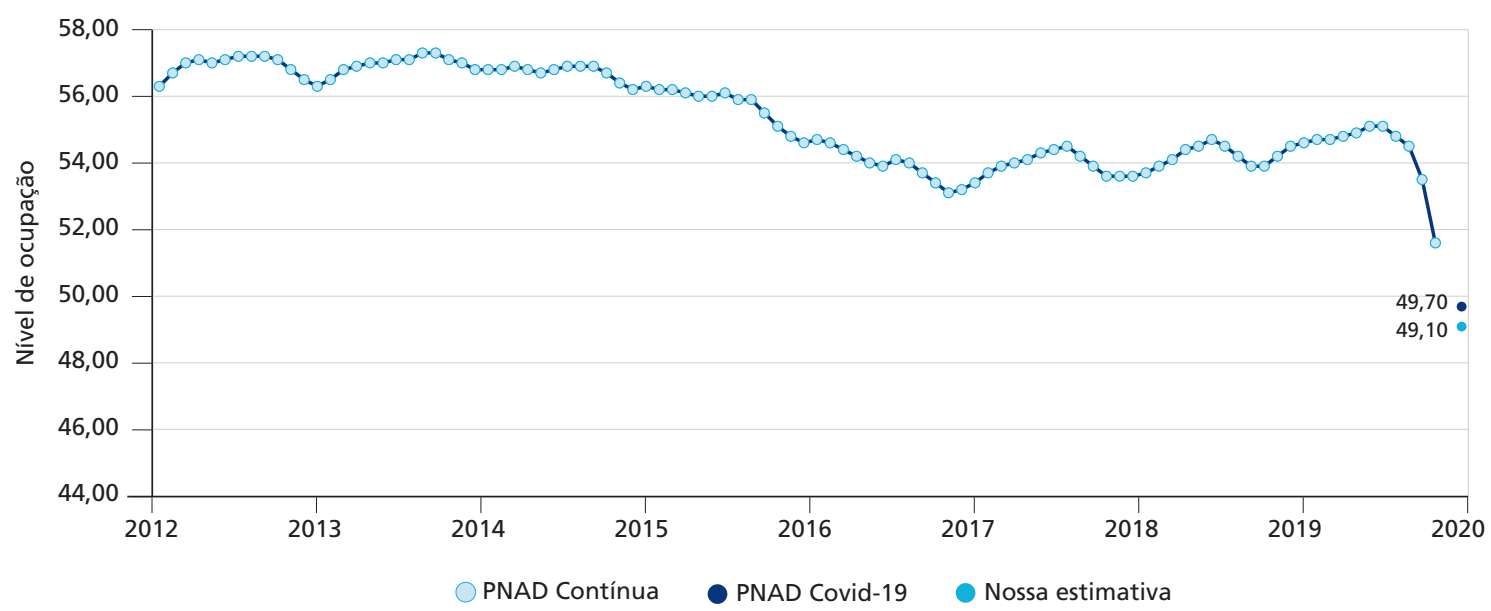

Fontes: PNAD Contínua - trimestres móveis (disponível em: <https://bit.ly/305ilkm>); PNAD-Covid 19 - indicadores semanais (divulgação de 16 de junho de 2020); e PNAD Contínua 2019 - período anual (primeiras visitas).

Elaboração dos autores. 
A taxa de desocupação que estimamos parte do suposto de que um indivíduo desligado de um posto de trabalho permanece na população economicamente ativa (PEA) - nosso modelo não distingue entre aqueles que continuam a buscar trabalho e aqueles que se recolhem à inatividade. Segundo dados da PNAD-Covid-19, a taxa de desocupação na última semana de maio teria sido de 11,4\% (contra 11,7\% de nosso baseline e 12,6\% na PNAD Contínua do trimestre de fevereiro a abril de 2020). Entretanto, a PNAD-Covid-19 captou também indivíduos fora da força de trabalho que náo procuraram trabalho por conta da pandemia ou por falta de trabalho na localidade, mas que gostariam de trabalhar, cerca de 17,7 milhóes de pessoas. Esses seriam indivíduos que se recolheram à inatividade justamente em função das medidas de distanciamento social. Para efeitos de comparação, é possível sugerir uma medida de desemprego oculto pelo distanciamento social simplesmente adicionando esse número à PEA efetiva. Assim, obtemos uma taxa de desocupação ampliada de 25,2\% - tal valor se aproxima dos $21,7 \%$ que estimamos no cenário 3 .

\subsection{MP no 936/2020 e RBE ao longo dos cenários sequenciais}

Nesta subseção, adicionamos aos cenários sequenciais de desemprego a incidência da MP no 936/2020 e da RBE. Assumimos que essa medida provisória incide sobre os três estágios intermediários exceto sobre o baseline e sobre a última etapa, em que vige o cenário 3 de desemprego. Ou seja, os gráficos sugerem uma sequência temporal, iniciando-se com o desemprego anterior à pandemia, depois com três cenários de crescimento de desemprego e como a incidência das políticas emularia um momento "atual" da pandemia. E então observamos o que ocorreria com a renda domiciliar per capita média, o coeficiente de Gini e a taxa de pobreza se a RBE não tivesse ocorrido, se o valor do benefício fosse $\mathrm{R} \$ 300,00$ e o que estaria ocorrendo com o valor atual, de $\mathrm{R} \$ 600,00$. O painel de gráficos 3 e 4 exibe esses resultados.

Os resultados sobre a renda domiciliar per capita indicam que a queda teria sido drástica sem a presença da RBE. Como indicado na subseção 5.2, é plausível pensar que, no início de junho de 2020, o Brasil experimenta o cenário 3. O benefício da RBE no valor de R $\$ 600,00$ eleva a renda domiciliar per capita em todos os cenários de desemprego. Um hipotético benefício no valor de $\mathrm{R}$ \$ 300,00 restituiria parcialmente e com oscilaçôes algumas perdas da renda. É importante considerar que, de um ponto de vista epidemiológico, a RBE tem também um caráter preventivo: o de incentivar as pessoas a cumprirem medidas de distanciamento social, evitando, por exemplo, que saiam para trabalhar (no caso de contas-própria) ou procurar emprego. Além disso, é preventiva também com respeito aos próprios efeitos sobre o mercado de trabalho. Assim, o valor de R \$300,00 mostra, na realidade, sua insuficiência e inadequação.

A pobreza, medida apenas em termos monetários, é reduzida por benefícios de ambos os valores, mas com muito maior intensidade no valor de $\mathrm{R} \$ 600,00$. Isso ocorre porque a renda dos estratos mais pobres já é usualmente inferior ao valor médio per capita dos benefícios - o que mostra, na realidade, as crônicas condiçóes de privação dessas camadas. As tendências para o coeficiente de Gini mostram que o auxílio emergencial é equalizador. Com o valor de $\mathrm{R} \$$ 600,00 por três meses, cairia de 0,543 para 0,463 - uma queda de, aproximadamente, $14,5 \%$. 
Para o valor de $\mathrm{R} \$ 300,00$, essa queda teria sido de 7,4\%, e o coeficiente de Gini atingiria a casa dos 0,503 . Isso evidencia que o foco nos mais pobres e informais tem um efeito nivelador da hierarquia de rendimentos.

$\mathrm{Na}$ ausência de qualquer benefício dessa natureza, a desigualdade teria aumentado de modo constante e rápido. A renda domiciliar per capita teria caído cerca de R \$95,00, o coeficiente de Gini subiria para 0,560 e a pobreza teria crescido aproximadamente 3,2 p.p., atingindo $22 \%$ da população.

\subsection{Distribuição do desemprego provocado pela pandemia, da MP no 936/2020 e da RBE ao longo dos estratos de renda}

O desemprego usualmente é mais concentrado na base da distribuição. O gráfico 3 mostra a distribuição dos desocupados em 2019, ao longo dos estratos de renda domiciliar per capita. ${ }^{10}$ Trata-se de uma contagem de domicílios, não de indivíduos: se um domicílio apresenta, pelo menos, um membro desempregado, o domicílio todo é contato como afetado - uma vez que os impactos sobre a renda domiciliar serão sentidos por todos os moradores. O que verificamos é uma distribuição assimétrica à direita, concentrada entre os mais pobres.

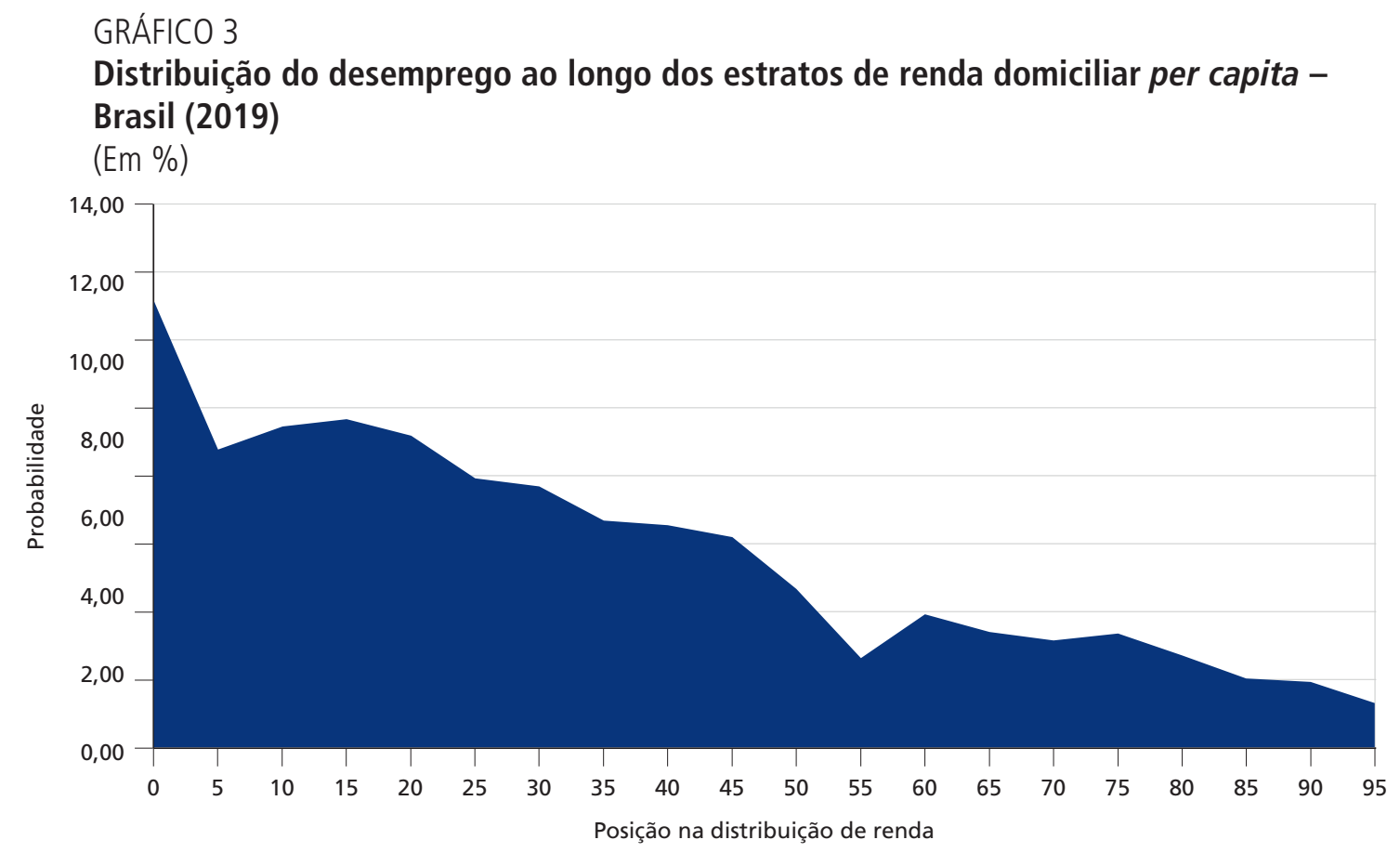

Fonte: PNAD Contínua 2019 - período anual (primeiras visitas).

Elaboração dos autores.

10. A soma dos percentuais ao longo dos estratos de renda é $100 \%$. 
Seguindo a lógica, o gráfico 4 apresenta como o desemprego provocado pela pandemia, os acordos da MP n⿳9 936/2020 e a incidência da RBE se distribuem ao longo dos estratos de renda. Observamos que o desemprego e a perda de renda decorrentes da pandemia distribuem-se de forma mais homogênea e com mais concentração nas camadas médias. Isso significa que esse grupo, usualmente não exposto a riscos de perda de renda e emprego, encontra-se, nesse contexto extraordinário, vulnerabilizado, do ponto de vista socioeconômico. O desemprego atual atinge ainda, de forma inédita, uma parcela considerável dos trabalhadores situados na parte superior da distribuição de renda.

\section{GRÁFICO 4}

Distribuição do desemprego provocado pela pandemia, da MP no 936/2020 e da RBE ao longo dos estratos de renda

(Em \%)
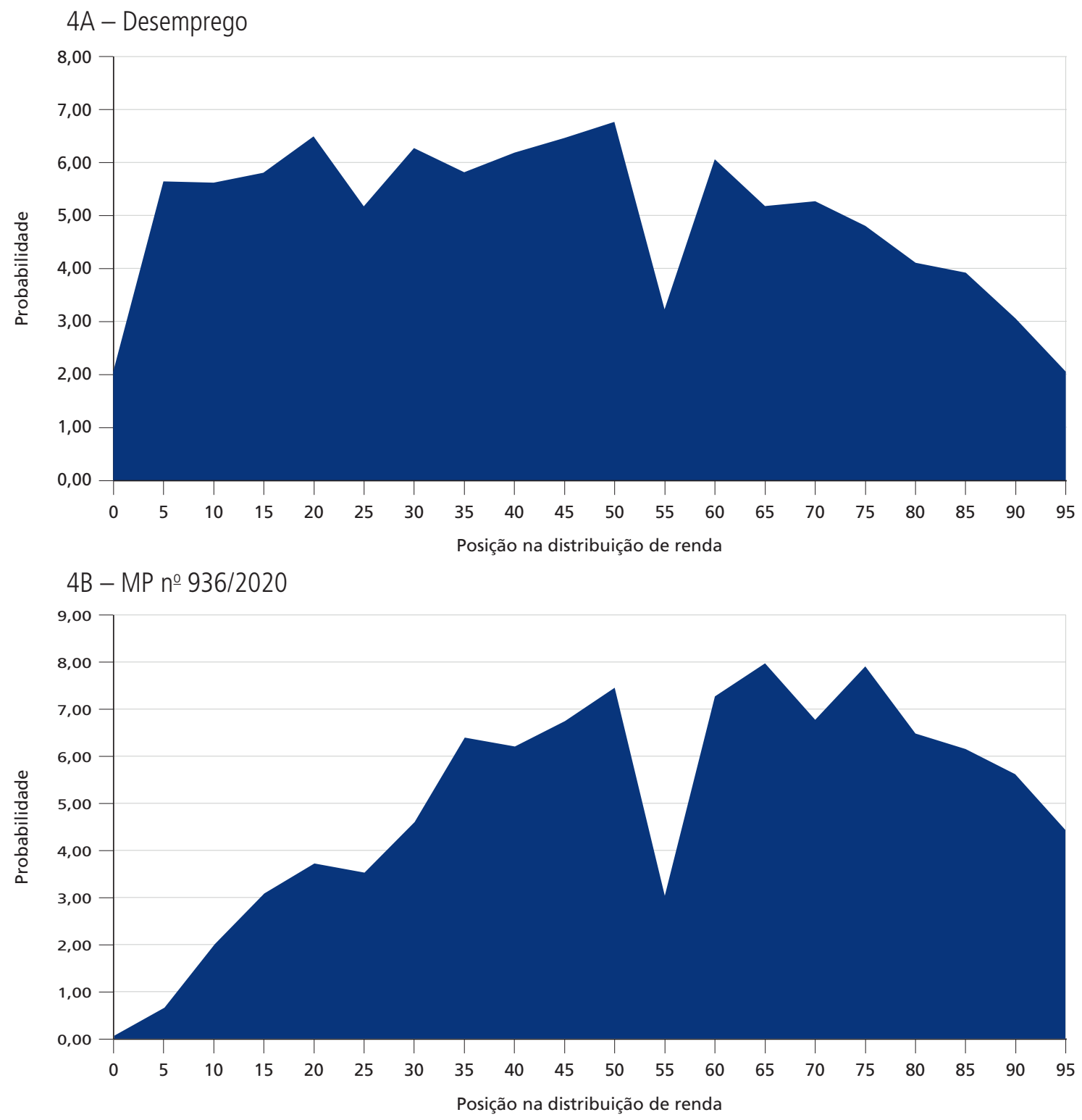


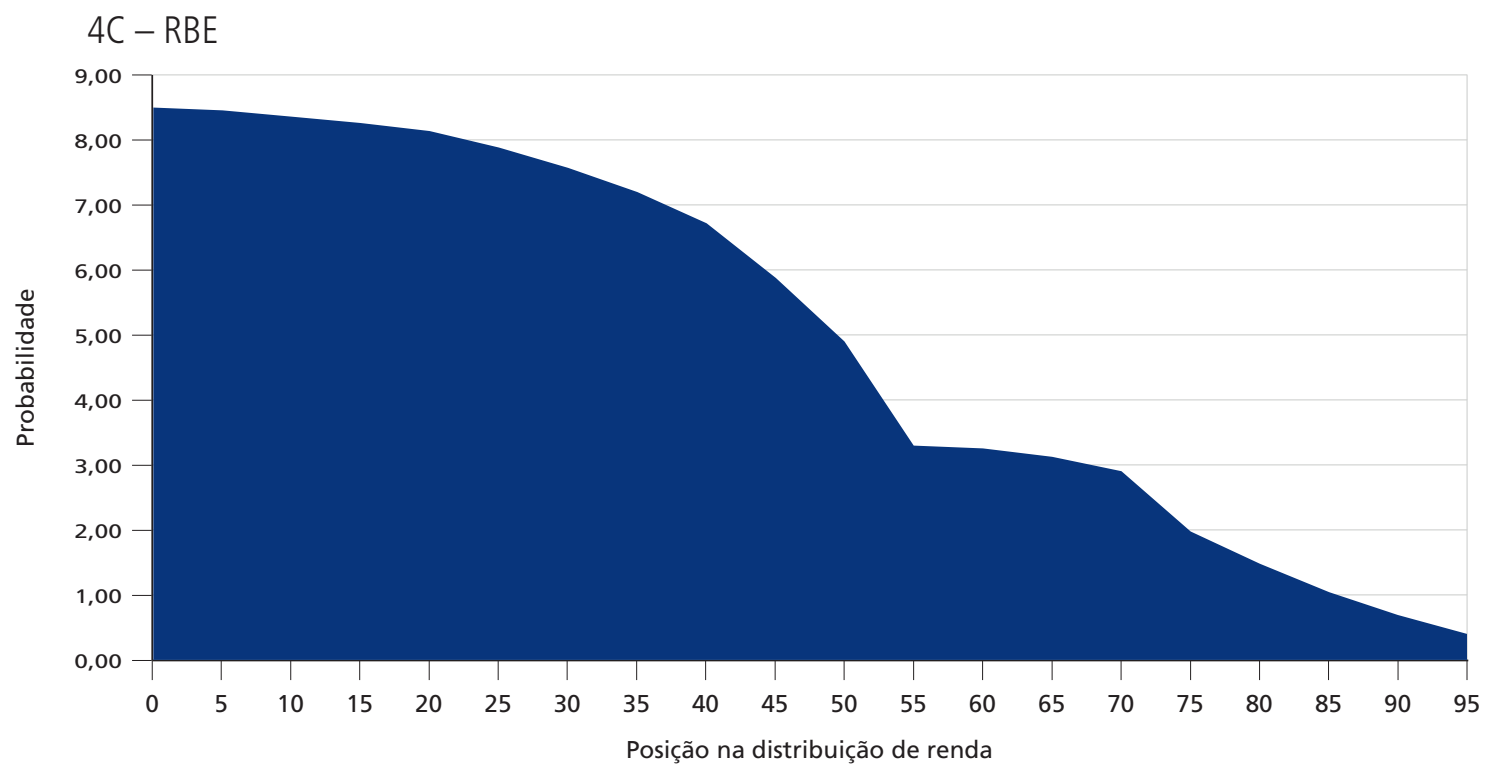

Fonte: PNAD Contínua 2019 - período anual (primeiras visitas).

Elaboração dos autores.

A incidência da MP no 936/2020, embora atinja trabalhadores em todos os níveis de renda, é assimétrica à esquerda, concentrando-se nos estratos médio-altos. Isso decorre dos critérios de elegibilidade do programa, visto vez que o vínculo formal de emprego é mais frequente nessas camadas. É notório o "vale" que ocorre tanto na distribuição do desemprego como na MP no 936/2020 exatamente no estrato localizado entre os percentis P55 e P60. Isso ocorre porque nesse ponto da distribuição há um amplo número de famílias cuja renda é decorrente de aposentadorias, pensóes e benefícios (como o Benefício de Prestação Continuada - BPC). A RBE, por sua vez, é assimétrica à direita, concentrando-se nas camadas baixas, onde se concentram também os trabalhadores informais. O benefício não é, contudo, focalizado, uma vez que, mesmo entre os $25 \%$ mais ricos, ainda é possível encontrar elegíveis.

\section{CONSIDERAÇÕES FINAIS}

A pandemia afetou a atividade econômica de modo inédito, causou uma queda drástica do nível de ocupação ao forçar as pessoas a se retirarem do mercado de trabalho e forçou o governo a implementar políticas emergenciais. Tal conjunto de excepcionalidades exige inovação analítica, mas, também, cautela na análise dos resultados.

O desemprego aberto de 9,6\% identificado pela PNAD-Covid-19 não pode ser lido sem ressalvas. Nesse contexto, sugerimos que a mudança de caráter quantitativa $e$ qualitativa sem precedentes na procura por trabalho exige considerar, para efeitos de comparação com os cenários estimados pré e pós-pandemia, o desemprego oculto pelo distanciamento social. Sob esses termos, o desemprego ampliado seria de 25,3\% na PNAD-Covid-19 e de 21,7\% na nossa estimativa mais realista. Além disso, de forma inédita e em maior intensidade do que em crises anteriores, o desemprego atingiu indivíduos localizados nas partes intermediária e superior da distribuição de renda, tornando-se menos assimétrica à esquerda. 
Observamos que a RBE no valor de $\mathrm{R} \$ 600,00$ eleva a média da renda domiciliar per capita em R \$ 178,00 e é exitosa em proteger os mais pobres, ao menos em termos das privaçóes monetárias. Os impactos temporários sobre a pobreza e a desigualdade são também muito expressivos, mas é importante pontuar que a renda domiciliar per capita torna-se um indicador mais limitado de pobreza no atual cenário.

Os efeitos da MP no 936/2020 são de menor magnitude, concentram-se na metade superior da distribuição de renda e causam uma redução de, aproximadamente, $R$ \$ 30,00 na renda domiciliar per capita e uma leve queda de 0,003 no coeficiente de Gini. Há também um pequeno efeito de aumento da pobreza.

No limite, alguns de nossos resultados poderiam até mesmo sugerir que o quadro social do país durante a pandemia, mensurados por indicadores usuais (desocupaçáo, renda domiciliar per capita, pobreza monetária e desigualdade), estaria aparentemente melhor do que no cenário pré-pandemia. Essa afirmaçáo, contudo, chega a ser absurda e coloca em evidência o limite dos indicadores convencionais para caracterizar um momento tão excepcional.

Passada a pandemia, a economia estará ainda no fundo do poço. Extinta a RBE - e sem outro programa que a substitua, mesmo que menos generoso -, a pobreza pode atingir um quarto da populaçáo e a desigualdade crescer vertiginosamente para patamares que náo víamos desde os anos 1980. Evitar esse legado da pandemia por meio de um sistema de proteção social sólido é um dos principais desafios para os tempos futuros.

\section{REFERÊNCIAS}

BARBOSA, R. et al. Auxílio de R\$ 600,00 precisa continuar e pode ser financiado por contribuição emergencial sobre altas rendas. Boletim: Rede de Pesquisa Solidária Políticas Públicas \& Sociedade, v. 8, maio 2020.

BRASIL. Ministério da Economia. Estatísticas mensais do emprego formal - Novo Caged. Brasília: ME, 2020. Disponível em: <https://bit.ly/3eg074u>. Acesso em: 13 jul. 2020.

COSTA, J. S. M.; REIS, M. C. Uma análise da MP no 936 sobre os rendimentos dos trabalhadores e a renda domiciliar per capita. Brasília: Ipea, maio 2020. (Nota Técnica, v. 71).

ELBERS, B. Shapley: R package for computing shapley-shorrocks value decompositions. New York: Columbia University, 2019.

HECKSHER, M. D. Valor impreciso por mês exato: microdados e indicadores mensais baseados na PNAD Contínua. Brasília: Ipea, abr. 2020. (Nota Técnica, v. 62).

HECKSHER, M. D.; FOGUEL, M. N. Benefícios emergenciais aos trabalhadores informais e formais no Brasil: estimativas das taxas de cobertura combinadas da Lei $\mathrm{n}^{-} 13.982$ e da MP no 936. Brasília: Ipea, abr. 2020. (Nota Técnica, v. 66).

KOMATSU, B.; MENEZES-FILHO, N. Simulaçóes de impactos da Covid-19 e da renda básica emergencial sobre o desemprego, renda, pobreza e desigualdade. São Paulo: Insper, abr. 2020. (Policy Paper, v. 43). 
SHORROCKS, A. F. Decomposition procedures for distributional analysis: a unified framework based on the Shapley value. The Journal of Economic Inequality, v. 11, n. 1, p. 99-126, 1은 mar. 2013.

SOUZA, P. H. G. F. et al. Estimativas de público elegível e custos do benefício emergencial criado pelo PL no 9.236/2017. Brasília: Ipea, mar. 2020. (Nota Técnica, v. 60). 
